\title{
The Social Environmental Elements of Resilience among Vulnerable African American/Black Men who have Sex with Men
}

Mance E. Buttram

Nova Southeastern University, mance.buttram@nova.edu

Follow this and additional works at: https://nsuworks.nova.edu/shss_facarticles

Part of the Medicine and Health Sciences Commons, and the Sociology Commons

\section{NSUWorks Citation}

Buttram, M. E. (2015). The Social Environmental Elements of Resilience among Vulnerable African American/Black Men who have Sex with Men. Journal of Human Behavior in the Social Environment, 25 (8), 923-933. https://doi.org/10.1080/10911359.2015.1040908

This Article is brought to you for free and open access by the Faculty Scholarship at NSUWorks. It has been accepted for inclusion in CAHSS Faculty Articles by an authorized administrator of NSUWorks. For more information, please contact nsuworks@nova.edu. 


\section{The Social Environmental Elements of Resilience Among Vulnerable African American/Black Men Who Have Sex With Men}

\section{Mance E. Buttram}

To cite this article: Mance E. Buttram (2015) The Social Environmental Elements of Resilience Among Vulnerable African American/Black Men Who Have Sex With Men, Journal of Human Behavior in the Social Environment, 25:8, 923-933, DOI: 10.1080/10911359.2015.1040908

To link to this article: https://doi.org/10.1080/10911359.2015.1040908

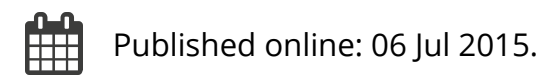

Submit your article to this journal ¿

山 Article views: 271

Q View related articles ¿

View Crossmark data ¿

Citing articles: 16 View citing articles $\sqsubset$ 


\title{
The Social Environmental Elements of Resilience Among Vulnerable African American/Black Men Who Have Sex With Men
}

\author{
Mance E. Buttram \\ Center for Applied Research on Substance Use and Health Disparities, Nova Southeastern \\ University, Miami, Florida, USA
}

\begin{abstract}
Resilience theory has been suggested as a strong framework for research on HIV prevention among men who have sex with men (MSM). Among this population, literature indicates that African American/Black MSM are particularly vulnerable to health and social disparities associated with HIV transmission risk. Conceptualizing resilience as a part of one's social environment, this qualitative study investigates the specific elements of resilience, and the associated contexts and relationships, among a sample of 21 substance-using African American/Black MSM. Data indicate that (1) elements contributing to resilience are multiple and co-occurring, including inner strengths, social relationships, diversity of experience, religion/spirituality, altruism, and creativity; (2) as an element of resilience, social support was experienced differently among men who did and did not have supportive relationships with other gay and bisexual men, which has implications for social service provision and intervention approaches; and (3) diversity of experiences and relationships is an important influencing factor on expressions of resilience. Social services or interventions that facilitate the development of these elements of resilience will likely be especially beneficial for vulnerable African American/Black MSM.
\end{abstract}

Keywords: African American, HIV, men who have sex with men, qualitative, resilience, substance use

\section{INTRODUCTION}

Over the last 40 years, a great body of literature has theorized the concept of resilience in which consensus has built around that idea that resilience is a dynamic process wherein individuals are capable of positive adaptation or resistance, recovery, coping, and success within the context of adversity (Luthar, Cicchetti, \& Becker, 2000; Masten, 2001). The process of positive adaptation occurs through protective factors or assets and resources that facilitate a positive outcome for individuals exposed to risk (Wright \& Masten, 2006). Thus, for individuals to be resilient, they must have experienced some form of risk and utilized protective factors to adapt positively (Kolar, 2011). Although risk exists for everyone, and risk factors need to be assessed, the emphasis of resilience research is on protective or enabling factors (Obrist, Pfeiffer, \& Henley, 2010).

Address correspondence to Mance E. Buttram, Center for Applied Research on Substance Use and Health Disparities, Nova Southeastern University, 2 N.E. 40th Street, Suite 404, Miami, FL 33137, USA. E-mail: mance.buttram@nova.edu 
Using a framework more closely aligned with anthropology, recent literature advances the idea that resilience is also a quality of an individual's social environment (Liebenberg \& Ungar, 2009). Building on this perspective, resilience has recently been defined as "the process of harnessing biological, psychosocial, structural, and cultural resources to sustain wellbeing," (Panter-Brick \& Leckman, 2013, p. 333), while at the same time resilience is a process in which one is actively interacting with his or her environment (Southwick, Bonanno, Masten, Panter-Brick, \& Yehuda, 2014). A social ecological perspective on resilience seeks to identify the context, relationships, and processes that create positive growth, in addition to understanding how agency and resourcefulness allow individuals to seek out necessary resources and call for resources to be provided in culturally meaningful ways (Liebenberg \& Ungar, 2009; Ungar, 2011). Thus, resilience researchers must identify when, how, and for whom do specific resources matter (Panter-Brick, 2014) to develop effective interventions and social services to maximize positive growth and development (Luthar \& Brown, 2007).

Recently men who have sex with men (MSM) have been receiving much attention with regard to resilience in the context of HIV prevention, because of the multiple HIV-related health and social disparities experienced by this population (Herrick, Stall, Goldhammer, Egan, \& Mayer, 2014; Kubicek et al., 2009; Kubicek, McNeeley, Holloway, Weiss, \& Kipke, 2013; Kurtz, Buttram, Surratt, \& Stall, 2012). Moreover, literature indicates that African American/Black MSM experience greater rates of health and social disparities than other MSM, including HIV incidence, substance use, victimization and gang involvement, incarceration, and poor physical health (Garofalo, Mustanski, Johnson, \& Emerson, 2010; Harawa et al., 2008; Hatfield, Horvath, Jacoby, \& Rosser, 2009; Mays, Cochran, \& Zamudio, 2004; Prejean et al., 2011; Tobin, German, Spikes, Patterson, \& Latkin, 2011). Furthermore, structural homophobia is well documented within African American society (Díaz, Peterson, \& Choi, 2008), and it has been suggested that health inequalities among African American/Black MSM, such as HIV infection and victimization, may be attributed to homophobia and stigma within African American society (Harawa et al., 2008; Mays et al., 2004).

Conceptualizing resilience as a part of one's social environment, this qualitative study investigates resilience among a sample of substance-using African American/Black MSM. Data from in-depth interviews describe the multiple and various elements that contribute to resilience among this population. Furthermore, data explain how resilience resources are co-occurring and interwoven in the men's lives. Specificially this study is guided by the research question: What are the elements of resilience that are available and accessible to substance-using African American/ Black MSM?

\section{METHODS}

\section{Project ROOM Procedures}

Qualitative interviews were conducted with African American/Black MSM recruited from among participants in a two-armed randomized controlled behavioral intervention trial, Project ROOM. This study tested the efficacy of a novel four-session small group sexual and substance use risk reduction intervention compared to an enhanced efficacious HIV risk-reduction counseling condition targeting high-risk not-in-treatment MSM substance users in Miami-Ft. Lauderdale, Florida. See Kurtz, Stall, Buttram, Surratt, and Chen (2013) for a full description of the study procedures, assessments, interventions, and outcomes. Men eligible for Project ROOM were ages 18-55, reported unprotected anal intercourse with a nonmonogamous partner(s) during the past 90 days, and met one or more of three substance use inclusion criteria during the past 30 days: binge drinking (five or more drinks) at least three times, using marijuana on 20 or more days, or using any other drug at least three times. 


\section{Qualitative Data}

The current study uses newly collected qualitative data to answer the research question. In-depth interviews conducted by the author allowed for the collection of rich data, which were unable to be obtained during Project ROOM study assessments. Qualitative interviews were guided by a semistructured protocol asking about life history, social environment, self-perception of risk, and assets and resources. Each interview lasted approximately 90 minutes and took place in a private office. Participants were compensated $\$ 50$ for their time and travel expenses. Research protocols were approved by the Institutional Review Boards at Nova Southeastern University and Florida International University.

Project ROOM assessments included measures of demographics, substance use, sexual behavior, syndemic conditions, and social support. Men included in the present study were not significantly different from the other African American/Black MSM on these measures, which have been presented elsewhere (Buttram \& Kurtz, 2015; Buttram, Kurtz, \& Surratt, 2013; Kurtz et al., 2013). Project ROOM included 108 African American/Black MSM at baseline, of which $85.2 \%(N=92)$ completed the 12 month follow-up assessment. All 12-month completers were eligible to participate in the present qualitative study if they were able to be contacted through phone or e-mail. All contacted men agreed to participate. In total, 21 (22.8\%) BMSM Project ROOM completers participated in qualitative interviews.

\section{Present Study Procedures}

Qualitative interviews were conducted between May and August 2013. A semistructured interview protocol was used for the interviews, in which an interview guide was followed to ensure that all necessary topics were covered during the interview. The semistructured interview guide was developed with a focus on the social environment and resources (social, economic, and cultural) that are available and accessible to these men and self-descriptions of resilience. Semistructured interviewing allows for some flexibility so that respondents are provided the space to express themselves in their own terms and at their own pace (Bernard, 2011). Using this flexibility, the interviews were conversational in style with topics from the interview guide being discussed as they naturally occurred during the conversation, rather than maintaining a fixed interview format.

All qualitative interviews were digitally audio-recorded. During the data collection process, a data accounting log was used to track all collected data. A contact summary form collected basic information about each participant, in addition to describing and summarizing the most salient themes discussed during each interview (Miles, Huberman, \& Saldaña, 2014). Interviews were transcribed by an independent transcriptionist and reviewed for accuracy by the first author. Transcribed interviews were entered into ATLAS.ti version 7 software for data management, coding, and analysis.

\section{Analyses}

A grounded theory framework guided the data analysis (Glaser \& Strauss, 1967). In this method, the coding process is inductive and grounded in participants' voices. Each interview produces key concepts that are later linked to one another and analyzed to form formal theories (Bernard, 2011; Glaser \& Strauss, 1967).

Upon completion and transcription of each interview, preliminary codes were created by the first author using descriptive and in vivo coding schemes. Whereas descriptive codes use words or short phrases to summarize passages of data, in vivo codes use actual language from participants to name concepts and themes (Saldaña, 2013). In addition, extensive analytic memos were written after each participant was interviewed and after each interview was coded. Analytic memos were also written throughout the coding process to reflect on code choices, emergent themes and patterns, 
and conceptual models. Following the last participant interview, all transcribed interviews were coded for a second time to ensure that all coding was consistent throughout the dataset. Data collection was a cyclical process in which codes and memos were used to guide subsequent interviews, coding, and memo writing, as advocated by Saldaña (2013) and Glaser and Strauss (1967). Next, the data were themed (Saldaña, 2013), in which the final set of codes and their meanings were transformed into longer and more descriptive themes in order to organize recurrent meanings and patterns. Themes and definitions of themes were constantly compared across interviews to ensure consistency and reliability; validity was ensured through the use of thick, rich descriptions of data (Creswell, 2013).

\section{RESULTS}

Participants ranged in age from 20 to 52 (mean 40.8). Of the 21 participants, $20(95.2 \%)$ completed 12 or more years of education, $5(23.8 \%)$ were employed full time, and $8(38.1 \%)$ experienced homelessness during the past year. Eleven men (52.4\%) were HIV positive. At baseline assessment during participation in the original study, behaviors during the past 90 days included an average of 32.2 days high, 16.3 anal sex partners, and 25.1 unprotected anal sex times.

\section{Inner Strengths}

The most frequently mentioned elements of resilience were coded as "inner strengths." This category consists of individual attitudes, values, and behaviors, in addition to lessons learned from experiences of hard work and negative situations. During the interviews men described their inner strengths as simply part of who they are, "embedded," or "inside" of themselves. Descriptions included "strong-willed," "independent," "having a strong work ethic," "intuition," "strength," "humility," "motivation to succeed," and a desire to learn. The title "inner strength" signifies that these assets come from inside of the individual and are utilized as a result of individual agency, though they may be influenced by external factors.

A prominent subtheme was that though bad things happen in life, men can be happy with the good things in life and work toward fixing the bad things. One older man from Miami described having a philosophy of "life is good," which energized him and made him remember that he is happy with himself. He went on to say that even if he doesn't have a job or if bad things happen in life, he remembers that life is good and that "You can only do but so much. If something happens, you can only do 'A,' 'B,' and 'C,' so go get to doing 'A.' If that doesn't work, get to doing 'B,' and if that doesn't work, get to doing ' $C$,' and that's all you can do." Another respondent from North Miami said that "You'll never have it right in life. Just do what you have to do to take care of this situation and take care of that situation, and live that day, and then, go to the next day. If that same situation is there, deal with it again." A young man from Miami's Liberty City neighborhood compared his approach to life to a game of chess, in which he is thinking three moves ahead and looking for how to take care of himself now and for the next couple of years.

Another subtheme is the notion that hard work and previous experiences can build and strengthen a person's inner strengths. One young man from South Miami described learning a lot about himself and about life while training 20 hours per week in "blood, sweat, and tears" for dance competitions. An older participant from Miami's Overtown neighborhood told about his childhood, saying, "daily chores of feeding the chickens, pulling weeds out of the garden," and said that "it builds integrity." Still another man from South Miami described living in his own place and having to work from a very young age. These examples are illustrative of the ways in which men describe their life experiences as shaping their lives and, by extension, their inner strengths.

Life experiences, especially negative ones, were also important in developing inner strengths for these men. Describing his experiences of homophobia, one older man from Miami realized how 
strong he actually is and said, "I've been through some difficult situations, and I've survived them all alone. I've been through some things, and I've wandered them by myself, and I couldn't tell nobody, and I didn't." A young man from downtown Miami said that after going through his "dark phase" he had to "humble" himself and begin to rebuild his life. Doing so taught him that he is capable of such resilient actions and knows that everything is "cool" and will be okay. Similarly, one young man told about his experiences being on probation, after which he had to work hard to rebuild his reputation. He says, "One of the things that I learned is that people can change." An older man from Miami said that "If something was considered a mistake, it's a learning lesson, you know, where I try not to do it again. I point blank learn from it." Still other men noted the ways in which they started with nothing and "carved out a nice life" or learned to have a positive attitude after a bad work relationship with a coworker. These experiences, though different from person to person, further illustrate the ways in which inner strengths were developed and utilized individually, even if influenced by other social environmental elements.

\section{Social Relationships}

Social relationships are also important elements of resilience. A majority of 15 men described their social support networks as being made up of either family members or nongay friends. One young man from Miami said of his friendships, "A lot of them was people that I always had, but I was too high to see it. If I get into a financial bind, I have friends that I can call on, and even if they can't help me, at least they can get me a good solution." An older man from Miami, upon dealing with this substance use issues, realized that his biggest resource was the woman he works with. She encouraged him to reduce his drug use and included him in her family functions. In addition, through this process he began to become closer to his mother and brother. A similar experience occurred with another man who described finding social support among a pastor and outreach workers at a local ministry. He said, "They, like, see something in me that I couldn't see in myself. I have somebody too, you know, if I should ever need it."

Many men also described forming closer connections to family members. An older man from Miami began to get closer to his brother and nephews, who help him out with his health issues and living situation. A man from Ft. Lauderdale described a similar experience with a family member who continually checks on him, makes sure his basic needs are met, and is there for him in times of need. A Miami man said that now "My sister and mom, they're my resources." A man from Ft. Lauderdale stated that his sister has his back and that "If things really got haywire in any point in my life, I know whatever it took, my sister would be there, as well as I would be there for her."

Several other men stated that their social support is largely found among friendships that they have maintained for many years. "A couple of straight friends of mine, I've had them for a long time. They know that I'm gay; they know my status; they know everything else. I've been friends with them for so long it seems like it would be impossible to get rid of them now (laughs)," said one man. Two other men mentioned long-term friendships that have been supportive. As one said, "I have a good number of friends. Financial support, emotional support, talking back and forth, but you know, I mean, my social network is solid, I find. These are friends I've made over the years."

One additional respondent described the importance of a childhood role model:

The thing that turned me around was my neighbor, and she worked in corporate America and so she used to take me and my brother downtown, and her friends were professional people. And so I saw these, and this was my first time really seeing professional people, and you know being in a business environment and seeing all of that, I thought it was really exciting, the tall buildings. You know me, I'm an African American man and you know seeing Black men in suits and, you know, and meeting the presidents of companies and mangers, you know, seeing all of these positive people I'm like, "Wow!" "Wow!" This is what I want. 
From his account, one can see the importance of the relationship with his neighbor. Her actions introduced a new and diverse social environment. As a result, his aspiration to attain the same success facilitated the development of his inner strengths.

Unlike the respondents above, four men stated that a greater share of their social support was from gay friendships. Two men from Ft. Lauderdale who described their social support as a product of having a large core group of friends. Moreover, two men from Miami said they had supportive friendships that offered both financial and emotional support. One man from Ft. Lauderdale described how he made friends and connections with other gay men, and as a result, "we have this core group of, like, maybe like 12 of us, and we get together for holidays, and if it's one of our birthdays, we pick a restaurant and go out and we celebrate. We'll go dancing once in a while. We go to the film festivals." Another man from Ft. Lauderdale described it as, "a good place to be at, out of the closet, and a lot of social network going on, and a lot of things to do. You know they weren't against that, and you know, celebrated the gay lifestyle." One young man who grew up in Miami's Liberty City neighborhood said that he has many gay friends that he is close to, and he developed them after moving to Ft. Lauderdale to "redefine" himself. He also stated, "I still have relationships with my cousins and with some of my friends from back in the old neighborhood, but we just don't meet quite as often.

\section{Diversity}

Frequently discussed during the interviews was the diversity of people, experiences, places, and knowledge that heavily influenced men's lives. A majority of 13 men reported some form of diversity in their lives both in the past and in the present. One older man from Miami Beach said that his father was an airline pilot, which necessitated that the family moved often to many states. He went on to describe how much he liked traveling and such different places from the Deep South to the Midwest. He says now that diversity is still present in his life because he mingles with many different types of people.

Another man, who grew up in Massachusetts, described his neighborhood as racially/ethnically diverse; however, his was one of only three Black families in his town. That experience, he says, influences who he is today: "I wanna go to Europe. I wanna go to the hood sometimes. When I'm feeling hoodish, I'll go to Opa Locka. When I'm feeling European, I'm gonna go to Europe. You go out, expand your mind and meet different people, have different ideas, have different discussions."

A man from Miami Beach grew up in a part of Southern California that was "very mixed and diversified." He continued, "There can be racial tensions. There can be socioeconomic tensions. There can be political tensions when you mix a bunch of people together and I think it had its challenges, but I think there are more advantages than disadvantages." The exposure has made him more open to new things and ideas, and as a result, he traveled and worked abroad for several years, "Traveling around the world gave me a lot of confidence in my abilities of what I can and cannot do."

For men raised in South Florida, the exposure to diverse social networks, experiences, places, and knowledge was somewhat different. A South Miami man described his family's strong church involvement and mission activities as key to his diverse experiences. He said, "I was crosscultured. My parents had us with different ethnicities so I got to be with a lot of different kinds of people." Looking back, this respondent is able to see the value and uniqueness of his upbringing compared to others in his neighborhood:

Well the funny thing is I never thought that there was a difference, in with people, but I found out there was. Because, uh, people in the neighborhood was, "who those people coming to your house" or stuff like that. And I never thought it was a big deal until I was growing up and I was like, "Oh my God there is a difference." A lot of people didn't have what we had. A lot of things a lot of other people didn't do, we did. 
For some men, their diverse experiences were a result of participation in the armed forces, which brought them to live not only in other states, such as Oklahoma and South Carolina, but also overseas in Germany and the Netherlands. Men described "learning a lot about other people" and understanding more of the world. In addition to making some lifelong friends, men said they gained "strength" and "discipline" during their military service.

For others, exposure to diversity was present early on. Two older men described going to integrated schools. Said one man, "It really gave me a broader perspective of people, you know, to see that we're not all the same. It really taught me that people are different." A young man from South Miami also grew up in a community that was racially/ethnically mixed, which is evident in his current social relationships. One veteran had spent time in Turkey, Texas, and Key West, Florida. In part because of his experience, he says, "Why I love Miami so much is because of the diversity." Thus, his social network is heavily influenced by his desire to maintain diverse social connections.

A minority of five men described having more connection to gay social networks and the gay community, which in themselves are diverse experiences not generally present in the lives of a majority of the respondents. One man from Ft. Lauderdale described his travel experiences in which he visited San Francisco and was exposed to an openly gay environment. This influenced his decision to live in the Ft. Lauderdale suburb of Wilton Manors, a well-known gay enclave. Another young man told of his employment in the construction industry that required travel all over the country for months at a time. He says that this job, in part, inspired him to also move to Ft. Lauderdale and make connections with the gay community.

\section{Religion/Spirituality}

Religion/spirituality was mentioned by 12 men as being a key part of their lives. Respondents' comments indicate that religion/spirituality is an internal asset that men draw on to be resilient, and at the same time, it is also an external resource, especially when a church or religious organization offers needed assistance to vulnerable men. Many discussions of religion/spirituality began with childhood, as many men reported some sort of religious upbringing. Such an upbringing had an influence on the development of men's inner strengths and the use of inner strengths later in life. One older man from Miami said:

Upbringing in the church makes me hold on to my values and what I feel concerning me. I knew how to pray and the values that were instilled in my, you know, as a child that I found were useful as I got out in the world on my own. I learned to have regards for other people and their feelings, and for people in general. I learned how to go through things.

Another described a similar experience with religious upbringing and said, "When I became an adult it was, you know, it wasn't just church. I had a relationship with God. I had experiences with God where, you know, he brought me out of things, made peace. He helped me make peace with a lot of things in my life. My faith has always been strong and, you know, believing I can overcome anything."

In fact, inner strengths stemming from religious/spiritual experiences were common. A Miami man said that through prayer he is able to put things into perspective. Another man from Miami stated that, "What has really carried me through life is my faith. Even dealing with the HIV and all, it has kept me going." A young man from South Miami noted that prayer and reflection are things he needs and that, "It helps you keep it moving." For two men, though they aren't actively engaged in religious/spiritual activities currently, just knowing that God loves them has a positive effect on their abilities to cope with problems. Said one of the men, "In my mind, God made me, you know, and he knew what he was doing when he made me. He knew I was gay before I knew I was gay and they say God doesn't make any mistakes." 
Respondents also described religion/spirituality as an external resource that they actively seek out. For some, it is a resource to assist in coping with problems. A man from Miami described his most recent experience this way, "I went on Sunday. When I got home it was so peaceful. I went there and I just listened and you think, your problems are not as big as you think they are. It helps you clear your head and say, 'Okay, now I know what's really important.' And I needed that on Sunday." One Ft. Lauderdale man said, "Well I'm really stressed right now and so I really would like to go and get back involved in church." Another man also stated that he wanted to become more involved in church as an usher or choir member in part because of what he could learn from it in dealing with life.

Several other men mentioned more tangible resources that religion/spiritually offer. One older man from Miami's Overtown neighborhood told about his struggles with food insecurity and, at times, homelessness. The church he visits provides him with food and items he needs and assisted him in finding a place to live. He says, "When you give God praises, then he gives you blessings. I feel that, you know, because of me going to that church, not particularly to eat, but just to give God praises for the food that they will be giving later, and the help that we're given, that I got my place a lot faster." As mentioned above, a Ft. Lauderdale man credits the outreach of a local ministry with helping him secure social support, which led to him finding a job and secure living situation. A Miami man describes members from his church recommending books to guide him and help him deal with problems, in addition to counseling services. Another Miami man also mentions that he seeks out motivational reading, in addition to watching religious programs on television and using religious-based applications on his mobile phone for support.

\section{Altruism}

Besides social support and religion/spirituality, men also describe seeking resources in which to help others. Six men expressed such a desire, and most of them are actively engaged in some form of altruistic venture. Using skills they already possess, one man from Miami is searching out shelters and soup kitchens to serve as a cook, while another man realized he had a desire to teach and currently offers free computer and writing classes at a neighborhood community center. A third respondent from Ft. Lauderdale has completed the training necessary to volunteer at an animal shelter and is currently scheduled to go to orientation.

For two other men, their desires to help others stem from their own experiences of adversity. An older man said that following his HIV diagnosis in the 1990s he decided to get involved in the HIV community by volunteering as an HIV tester and peer counselor. Another young man said, "I would like to be in a place where maybe I can prevent someone from going through some of the things that I've had to go through to learn, what, you know, I know now. That's one of my aspirations is just to be able to help someone else from going through some of the shit that the world has to dish at you."

Men say that the wish to help others comes not only from their own experiences, but also because it is an innate desire. Through their volunteer efforts, respondents have also seen benefits in the form of additional social connections, an increase is business opportunities, and positive feelings generated from their efforts.

\section{Creative Outlet}

In addition to finding benefits in helping others, men in the study also reported that having a creative outlet was a positive part of their lives. Five men reported using poetry, design, photography, fashion, and dance as a way to express themselves and feel good. One young man, who has published three books, said, "I think I would go mad if I can't express myself in some form of writing." Another man stated that he is "very creative" and credits his ability to decorate and help others organize and design their homes to watching his mother do similar work in the church 
growing up. A third man described his love of photography in high school and now, in his early $40 \mathrm{~s}$, he has picked it up again. He says, "It's kind of like a second chance to do it again. You don't have to really talk, and you just visualize a form of art and click the camera, and I like doing that." For all of these men, doing something creative now only allows them to express themselves, but it also a way for them to spend their time productively.

\section{DISCUSSION}

The primary elements of resilience, as described during the interviews were inner strengths, social relationships, diversity of experience, religion/spirituality, altruism, and creativity. The data were themed to illustrate the distinct elements of resilience. Yet men's discussions of resilience indicate that key elements are interwoven, with each one contributing to a unified whole. Religion/ spirituality is a key theme that illustrates how elements of resilience are interwoven. For many men, the distinction between internal assets and external resources was somewhat blurry. Men described the positive influence of religion and spirituality on the development and utilization of inner strengths. At the same time, religion and spirituality provides external resources for these men including social support and relationships and basic needs.

Similarly, the influence of diversity is woven into the development and expression of resilience. As is seen in the interviews, diversity allows men to see other ways of understanding the world and, thus, not being so constrained by the political, economic, or social structures in which they are embedded. While diversity is not apparent in the literature as an element of resilience, descriptions from men in the study indicate that it is an important influencing factor in the development of resilience. Diversity plays a role in drawing attention to and revealing the existence of resources, in addition to fostering resourcefulness and agency necessary to obtain needed resources.

External resources, especially social relationships, were also key elements of resilience. Sources of social support, however, varied somewhat among the respondents. Though a small number of men described connections with other gay men, for a large majority of respondents, supportive social relationships were found with nongay individuals, such as family members or coworkers. This difference could potentially be an important aspect in the expression of resilience among MSM. The study of resilience must address the questions of when, how, and for whom resources matter (Panter-Brick, 2014); thus, further study of this phenomenon, comparing men who do and do not have supportive relationships with other gay individuals, may generate useful information about the expression of resilience as it relates to providing social services and developing interventions designed to facilitate resilient outcomes. Such a study would be especially relevant given the recently proposed hypothesis from HIV prevention researchers that connection to a sexual minority community may be a key element of resilience for MSM (Herrick et al., 2014).

A small number of men expressed that their supportive social relationships were with other gay or bisexual men. For these respondents, individual agency was expressed by seeking out and making connections to the gay community and creating a social environment in which their sexual orientation or same-sex behaviors could be freely disclosed. Thus, social support was more accessible for these men in a culturally meaningful way than for other men. Yet future research on resilience among this population may do well to examine how the expression of individual agency could be expanded to negotiate for structural changes that contribute to health and social disparities. Such an approach would focus on the availability of resources, such as culturally meaningful social support, in addition to the resourcefulness and agency of MSM to change their social environment (Panter-Brick, 2014). As has been noted by others, such a model that is focused on "changing the odds" in one's social environment is preferable to one in which individuals simply "beat the odds" stacked against them (Panter-Brick, 2014, p. 441; Ungar, 2008, pp. 220-221). Moreover, understanding resilience in this way would likely benefit the development of structural interventions or community approaches to ending the HIV epidemic among this population. 
Resourcefulness and agency are suggested by the themes of altruism and creativity. Nearly a third of men in this study described actively seeking opportunities to volunteer and contribute, including HIV testing and counseling. In addition, five men specifically discussed the importance of a creative outlet as keys to their health and well-being. Leveraging MSM's desires for altruistic or creative pursuits could also be important foundations from which to build HIV prevention efforts and identify targets for structural or community interventions.

This study has some limitations which must be noted. First, data presented are based on selfreport, and recall bias, interviewer effects, and social desirability bias are potential limitations. However, the use of a theoretically informed interview guide and strong rapport between participant and interviewer likely mitigated these effects. Second, many men from Project ROOM were unable to be contacted for the final qualitative interview, which took place more than a year following study completion. Thus, only men who had working phone numbers or e-mail addresses were able to participate in the qualitative portion of the study presented here. Finally, the men included in Project ROOM met specific substance use and sexual risk behavior eligibility criteria. Thus, these findings may not be generalizable to other populations of gay or bisexual men.

Data from African American/Black MSM in the study illustrate the many interwoven elements of resilience present in their lives. Many elements are common and experienced similarly among nearly all respondents. However, social support was experienced differently among men who had supportive social relationships with other gay or bisexual men, compared to men whose social supports were not gay or bisexual. This finding has important implications for social services and/ or interventions designed to promote the development of resilience among this population. Furthermore, increasing opportunities for diverse experiences for African American/Black MSM, as well as facilitating opportunities for creative expression and altruistic actions, will also likely benefit the development of resilience among this population. Such approaches are critically important given the structural health and social disparities faced by African American MSM.

\section{FUNDING}

This research was supported by an Early Career Investigator award from the Center for Applied Research on Substance Use and Health Disparities and DHHS Grant Number 5 R01 DA024579 from the National Institute on Drug Abuse. The content is solely the responsibility of the author and does not necessarily represent the official views of the National Institute on Drug Abuse or the National Institutes of Health.

\section{REFERENCES}

Bernard, R. H. (2011). Research methods in anthropology: Qualitative and quantitative approaches. New York, NY: AltaMira Press.

Buttram, M. E., \& Kurtz, S. P. (2015). A mixed methods study of health and social disparities among substance-using African American/Black Men who have sex with men. Journal of Racial and Ethnic Health Disparities, 2(1), 1-10. doi:10.1007/s40615-014-0042-2

Buttram, M. E., Kurtz, S. P., \& Surratt, H. L. (2013). Substance use and sexual risk mediated by social support among Black men. Journal of Community Health, 38(1), 62-69. doi:10.1007/s10900-012-9582-8

Creswell, J. W. (2013). Qualitative inquiry and research design: Choosing among five traditions. Thousand Oaks, CA: Sage.

Díaz, R. M., Peterson, J. L., \& Choi, K.-H. (2008). Social discrimination and health outcomes in African American, Latino, and Asian/Pacific Islander gay men. In R. J. Wolitski, R. Stall, \& R. O. Valdiserri (Eds.), Unequal opportunity: Health disparities affecting gay and bisexual men in the United States (pp. 327-354). New York, NY: Oxford University Press.

Garofalo, R., Mustanski, B., Johnson, A., \& Emerson, E. (2010). Exploring factors that underlie racial/ethnic disparities in HIV risk among young men who have sex with men. Journal of Urban Health, 87(2), 318-323. doi:10.1007/s11524-009$9430-\mathrm{z}$ 
Glaser, B. G., \& Strauss, A. L. (1967). Discovery of grounded theory: Strategies for qualitative research. Hawthorne, NY: Walter de Guyter.

Harawa, N. T., Williams, J. K., Ramamurthi, H. C., Manago, C., Avina, S., \& Jones, M. (2008). Sexual behavior, sexual identity, and substance abuse among low-income bisexual and non-gay-identifying African American men who have sex with men. Archives of Sexual Behavior, 37(5), 748-762. doi:10.1007/s10508-008-9361-x

Hatfield, L. A., Horvath, K. J., Jacoby, S. M., \& Rosser, B. R. S. (2009). Comparison of substance use and risky sexual behavior among a diverse sample of urban, HIV-Positive men who have sex with men. Journal of Addictive Diseases, 28 (3), 208-218. doi:10.1080/10550880903014726

Herrick, A. L., Stall, R., Goldhammer, H., Egan, J. E., \& Mayer, K. H. (2014). Resilience as a research framework and as a cornerstone of prevention research for gay and bisexual men: Theory and evidence. AIDS and Behavior, 18(1), 1-9. doi:10.1007/s10461-012-0384-x

Kolar, K. (2011). Resilience: Revisiting the concept and its utility for social research. International Journal of Mental Health Addiction, 9(4), 421-433. doi:10.1007/s11469-011-9329-2

Kubicek, K., McDavitt, B., Carpineto, J., Weiss, G., Iverson, E. F., \& Kipke, M. D. (2009). "God made me gay for a reason": Young men who have sex with men's resiliency in resolving internalized homophobia from religious sources. Journal of Adolescent Research, 24(5), 601-633. doi:10.1177/0743558409341078

Kubicek, K., McNeeley, M., Holloway, I. W., Weiss, G., \& Kipke, M. D. (2013). "It's like our own little world”: Resilience as a factor in participating in the ballroom community subculture. AIDS and Behavior, 17(4), 1524-1539. doi:10.1007/ s10461-012-0205-2

Kurtz, S. P., Buttram, M. E., Surratt, H. L., \& Stall, R. (2012). Resilience, syndemic factors, and serosorting behaviors among HIV-positive and HIV-negative substance-using MSM. AIDS Education and Prevention, 24(3), 193-205. doi:10.1521/aeap.2012.24.3.193

Kurtz, S. P., Stall, R. D., Buttram, M. E., Surratt, H. L., \& Chen, M. (2013). A randomized trial of a behavioral intervention for high risk substance-using MSM. AIDS and Behavior, 17(9), 2914-2926. doi:10.1007/s10461-013-0531-z

Liebenberg, L., \& Ungar, M. (2009). Introduction: The challenges in researching resilience. In L. Liebenberg \& M. Ungar (Eds.), Researching resilience (pp. 3-25). Toronto, Canada: University of Toronto Press.

Luthar, S. S., \& Brown, P. J. (2007). Maximizing resilience through diverse levels of inquiry: Prevailing paradigms, possibilities, and priorities for the future. Development and Psychopathology, 19(3), 931-955.

Luthar, S. S., Cicchetti, D., \& Becker, B. (2000). The construct of resilience: A critical evaluation and guidelines for future work. Child Development, 71(3), 543-562. doi:10.1111/cdev.2000.71.issue-3

Masten, A. S. (2001). Ordinary magic: Resilience processes in development. American Psychologist, 56(3), $227-238$. doi:10.1037/0003-066X.56.3.227

Mays, V. M., Cochran, S. D., \& Zamudio, A. (2004). HIV prevention research: Are we meeting the needs of African American men who have sex with men? Journal of Black Psychology, 30(1), 78-105. doi:10.1177/0095798403260265

Miles, M. B., Huberman, A. M., \& Saldaña, J. (2014). Qualitative data analysis: A methods sourcebook. Thousand Oaks, CA: Sage.

Obrist, B., Pfeiffer, C., \& Henley, R. (2010). Multi-layered social resilience: A new approach in mitigation research. Progress in Development Studies, 10(4), 283-293. doi:10.1177/146499340901000402

Panter-Brick, C. (2014). Health, risk and resilience: Interdisciplinary concepts and applications. Annual Review of Anthropology, 43, 431-448. doi:10.1146/annurev-anthro-102313-025944

Panter-Brick, C., \& Leckman, J. F. (2013). Editorial commentary: Resilience in child development-Interconnected pathways to wellbeing. Journal of Child Psychology and Psychiatry, 54(4), 333-336. doi:10.1111/jcpp.12057

Prejean, J., Song, R., Hernandez, A., Ziebell, R., Green, T., \& Walker, F., ... HIV Incidence Surveillance Group. (2011). Estimated HIV incidence in the United States, 2006-2009. PLoS ONE, 6(8), e17502.

Saldaña, J. (2013). The coding manual for qualitative researchers. Los Angeles, CA: Sage.

Southwick, S. M., Bonanno, G. A., Masten, A. S., Panter-Brick, C., \& Yehuda, R. (2014). Resilience definitions, theory, and challenges: Interdisciplinary perspectives. European Journal of Psychotraumatology, 5, 25338. doi:10.3402/ejpt. v5.25338

Tobin, K. E., German, D., Spikes, P., Patterson, J., \& Latkin, C. (2011). A comparison of the social and sexual networks of crack-using and non-crack using African American men who have sex with men. Journal of Urban Health, 88(6), 10521062. doi:10.1007/s11524-011-9611-4

Ungar, M. (2008). Resilience across cultures. British Journal of Social Work, 38(2), 218-235. doi:10.1093/bjsw/bcl343

Ungar, M. (2011). The social ecology of resilience: Addressing contextual and cultural ambiguity of a nascent construct. American Journal of Orthopsychiatry, 81(1), 1-17. doi:10.1111/j.1939-0025.2010.01067.x

Wright, M. O., \& Masten, A. S. (2006). Resilience processes in development: Four waves of research on positive adaptation in the context of adversity. In S. Goldstein \& R. Brooks (Eds.), Handbook of resilience in children (pp. 15-38). New York, NY: Springer. 